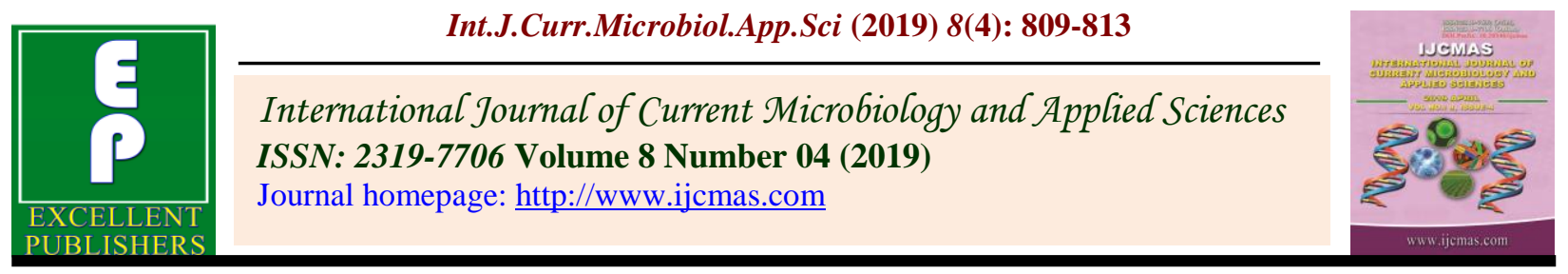

Original Research Article

https://doi.org/10.20546/ijcmas.2019.804.090

\title{
Helminthosporium vignicola- A New Report of Target Leaf Spot Disease of Cowpea Vigna unguiculata (L.) Walp. from Odisha, India
}

\author{
S. Sahoo* and S.K. Beura \\ Department of plant pathology, CA, Odisha University of Agriculture and Technology, \\ Bhubaneswar-751003, Odisha, India \\ *Corresponding author
}

\section{A B S T R A C T}

\section{Keywords}

Helminthosporium vignicola, Target leaf spot, Cowpea

Article Info

Accepted:

07 March 2019

Available Online:

10 April 2019
Helminthosporium vignicola, the incitant of target leaf spot of cowpea (Vigna unguiculata (L.) Walp.) is a foliar fungal pathogen experienced for the first time during kharif- 2017 from AICRP on Vegetable crops, OUAT, Bhubaneswar and adjoining coastal tracts of Odisha. The pathogen mainly infects the leaves, stems and fruits causing about 25-30\% loss in cowpea yield. The fungal pathogen was isolated, brought into pure culture and identified as Helminthosporium vignicola. The morphological and etiological aspects of fungus along with pathogenicity test have been carried out. Microscopic investigation revealed, the conidia are fusiform, pale to mid dark brown, widened at the middle, gradually tapering to round ends possessing 2-3 pseudosepta. The conidiophores are solitary or in groups, emerging from dark brown to black stromata, straight or flexous, sometimes geniculate, mid to dark brown and pale near apex and smooth. The dimension of the conidia is in the range of $13.0-32 \mu \mathrm{m} \times 5.1-11 \mu \mathrm{m}$ with an average range of $22.5 \mu \mathrm{m}$ $\times 8.05 \mu \mathrm{m}$.

\section{Introduction}

Cowpea (Vigna unguiculata) is an annual herbaceous legume crop mostly used as fodder, vegetable and a green manure crop. This crop is suited to hot and humid climates as well as to semi-arid areas. It is indigenous to Africa from which it was introduced into other tropical and subtropical countries (Cobley and Steele, 1975). It is grown all over India but in higher volumes in central and peninsular regions. It is largely grown as Kharif crop in some region of Maharashtra, Andhra Pradesh, Karnataka and Tamil Nadu. But in Odisha, cowpeas are mainly grown in uplands during kharif season in inland districts and under available soil moisture during rabi season in coastal districts. Cowpea is susceptible to fungal, bacterial and virus diseases, which can result in substantial loss in yield. Common diseases include blights, root rot, wilt, powdery mildew, rust and leaf spots. Among the leaf spot diseases, Helminthosporium leaf spot disease is a new emerging threat to all cowpea growers of Odisha. Therefore, an attempt has been made to identify the pathogen through normal procedures and subsequent studies have been undertaken on the pathogen. 


\section{Materials and Methods}

\section{Collection of disease sample}

Disease samples were collected from AICRP on Vegetable crops, OUAT, Bhubaneswar and adjoining coastal tracts of Odisha (Jatni, Balianta and Balipatna).

\section{Isolation of plant pathogen}

The leaves showing leaf spot symptoms were collected infected leaves were cut into small bits containing infected portions as well as apparent healthy portions. These bits were sterilized with $0.5 \%$ sodium hypochlorite for 2 minutes and then washed serially thrice to remove excess chemical. Then the bits were transferred to sterilized petriplates containing potato dextrose agar. The petriplates were kept in an incubator at room temperature of $26-28^{\circ} \mathrm{C}$ and the observations were taken periodically. After seven days of incubation, fungal colonies completely covered the plates and became black in colour indicating the production of spores.

\section{Purification and identification of the fungus}

Each isolate of fungus, maintained on PDA slants, were transferred to agar plates. Hyphae from the periphery of young colonies were carefully examined and transferred to PDA slants. This process was repeated for 2-3 times till the concerned fungus was found to be free from other fungi and bacteria. Pure culture of fungus was obtained through 'single spore' and 'hyphal tip' methods.

The characteristics of the fungal colony on PDA and the details of their morphology were recorded for each isolate. Each isolate was taxonomically identified with the help of available cultures and literature.

\section{Single spore isolation}

A spore suspension was prepared in sterile water and spore contents were ascertained by examining a drop of suspension under the microscope. Culture tubes containing $10 \mathrm{ml}$ of sterile water agar were melted over water bath and temperature was allowed to come down to $40^{\circ} \mathrm{C}$. A loop full of spore suspension from this tube was again transferred to second culture tube containing melted agar. Likewise a series of dilution of spores in the medium were prepared which in turn poured in to the sterilized petriplates one after another. All petriplates were incubated in an incubator at $28 \pm 1^{0} \mathrm{C}$.

After 24 hours of incubation, the petriplates were examined in an inverted position and germinating spores were located and marked with the help of glass marking pencil. A small amount of medium in the marked area containing germinating spores were transferred by means of a sterile inoculating needle to the middle of potato dextrose agar medium slant under aseptic condition. The slants with single germinating spore were incubated in a BOD incubator at $28 \pm 1^{\circ} \mathrm{C}$. After 2-3 days, the growth of the fungus was observed in the slant. Thus a pure culture was obtained.

\section{Hyphal tip isolation}

The fungus was grown in a sterile petridish containing potato dextrose agar medium. As isolated, hyphal tip was located under the microscope and marked with the help of sharp glass marking pencil. The tip was carefully lifted up and transferred by sterilized inoculating needle to a potato dextrose agar slant at room temperature. After 2-3 days, the growth of fungus was noticed in the culture tube and thus, a pure culture of the fungus was obtained and it was maintained by repeated sub- culturing. 


\section{Maintenance of culture}

The pure culture of the fungus was maintained on Potato Dextrose Agar (PDA) slants throughout the period of investigation. The fungus was subcultured at an interval of two months and stored at $25 \pm 1^{\circ} \mathrm{C}$.

\section{Identification of the culture}

The identification of fungal pathogen was done based on the spore morphology and colony characters (Barnett and Hunter, 1972) and Demataceous hyphomycetes (Ellis, 1971). To identify the pathogen, morphological and cultural characters of the fungus isolated from cowpea were studied in laboratory under the microscope and compared with the original monogram describing the morphological characterstics of the fungus.

\section{Proving pathogenicity}

Pathogenicity was proved on cowpea variety Utkal Manika. The healthy plants were raised in polybags. Two methods were used to undertake study.

The leaves of the plants were surface sterilized and were pin pricked with the help of sterilized needle. For inoculation, a suspension containing mycelia bits of the fungus was prepared by using sterilized water. Then, the suspension was sprayed on the pin pricked leaves.

The control plants were sprayed with only sterilized distilled water. After spraying, all the plants were covered with polythene bags and kept inside a glass house at $25^{\circ} \mathrm{c}$ and $95 \%$ $\mathrm{RH}$. Observations on occurance of disease symptom were taken periodically.

Some regions on the leaf lamina were selected and the places were marked by marker. The marked portions were smeared with mycelial bits by using a cotton plug. The control plants were smeared with sterilized distilled water.

The symptoms were appeared 4-5 days after inoculation and reisolation was made from such spots to prove pathogenecity according to koch's Postulate.

\section{Results and Discussion}

Target leaf spot disease of cowpea was found to be a major disease for all cowpea growers of coastal part of Odisha. Occasionally, this disease was also associated with the stem and pods which reduced the market value (Fig. 1$3)$.

Fig.1 (A) Pure culture in slants (B) Pure culture at seven days after inoculation (C) Pure culture at 15 days after inoculation (spore suspension)
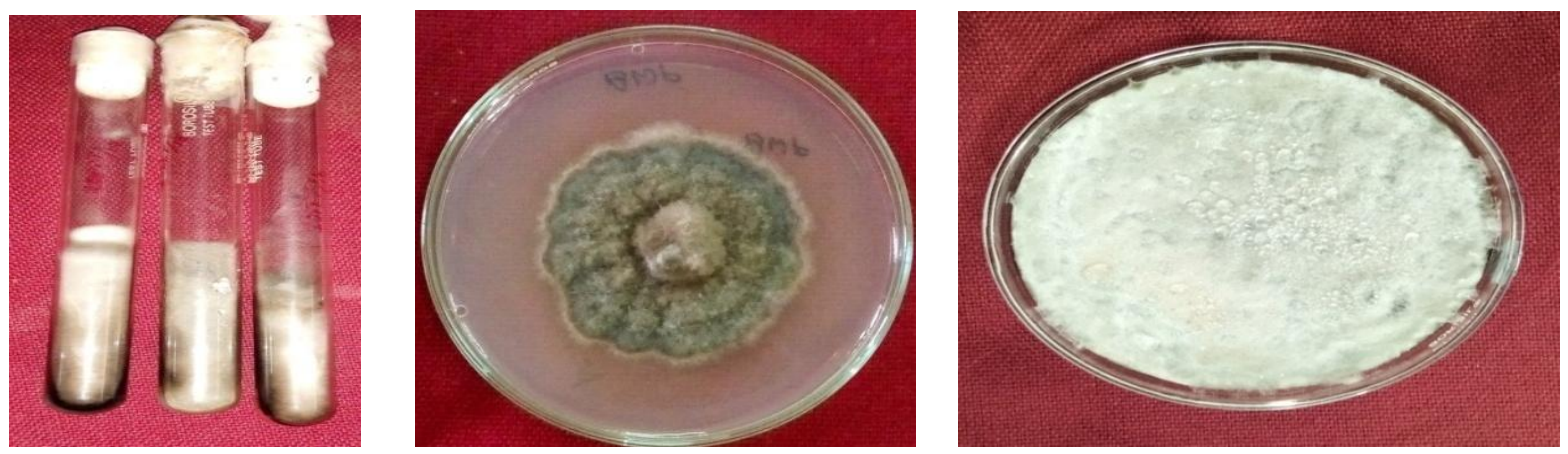
Fig.2 Microphotograph showing conidia and conidiophores
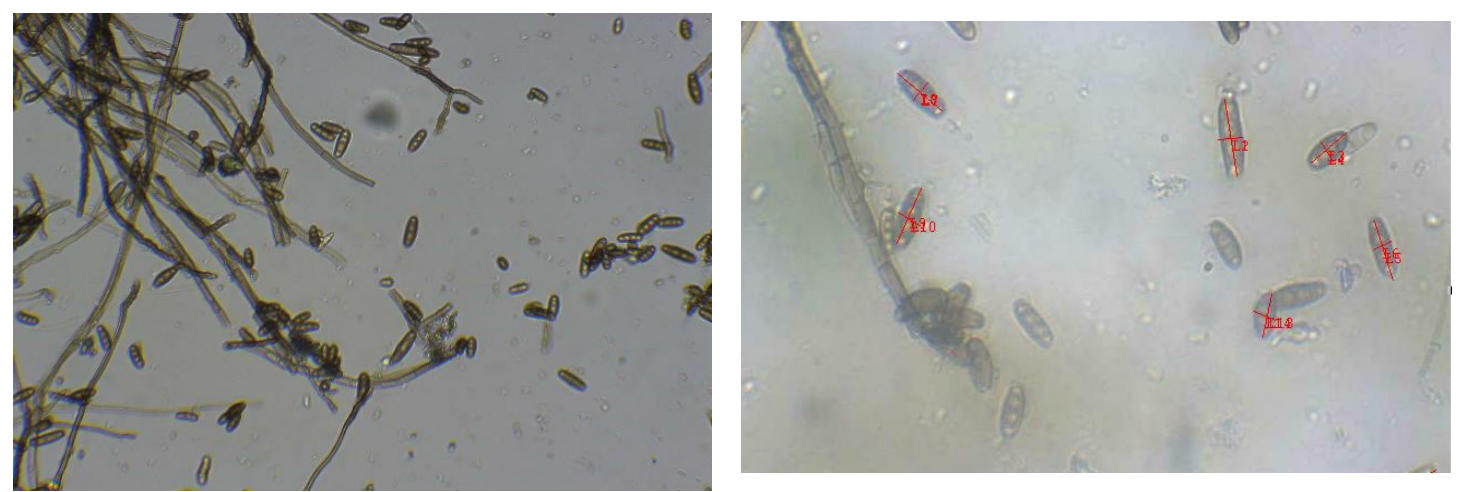

Fig.3 Pathogenicity test
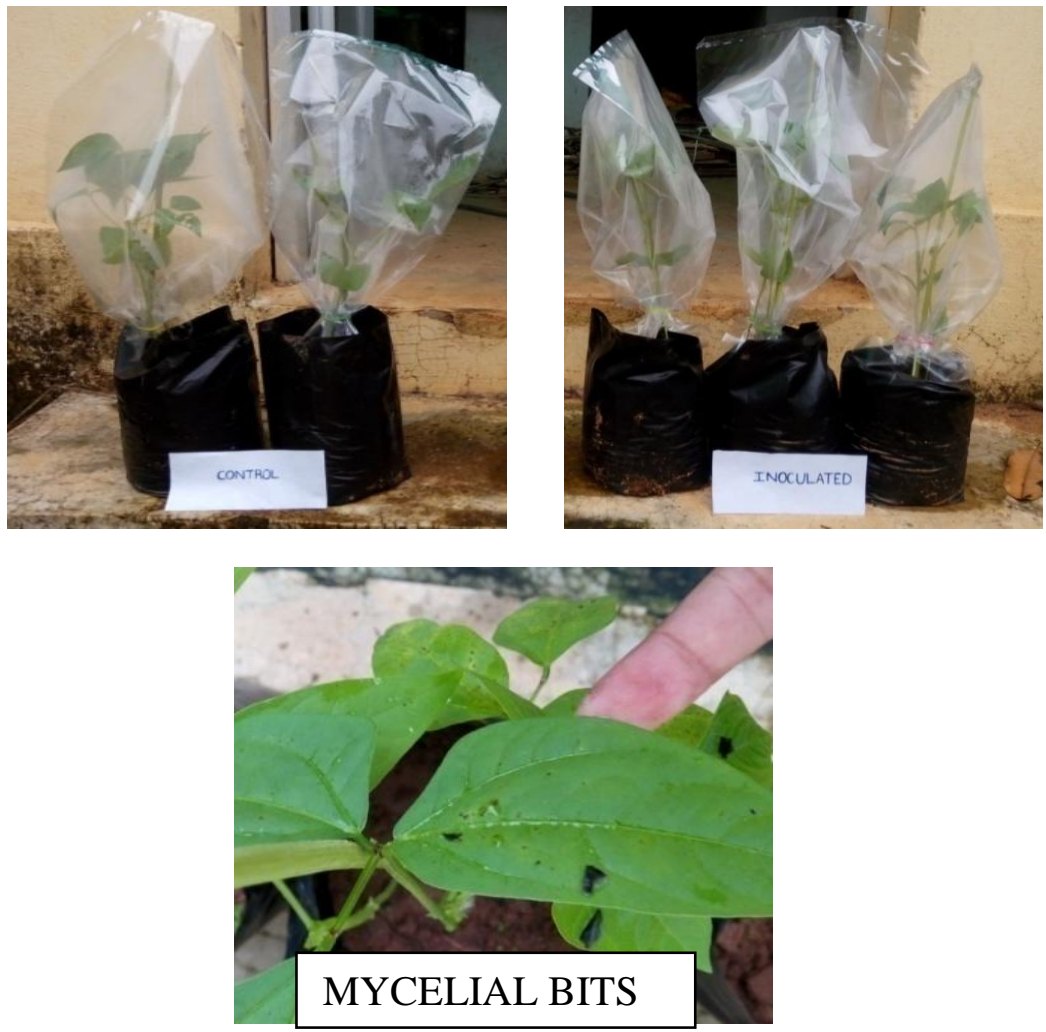

\section{THREE DAYS AFTER INOCULATION}
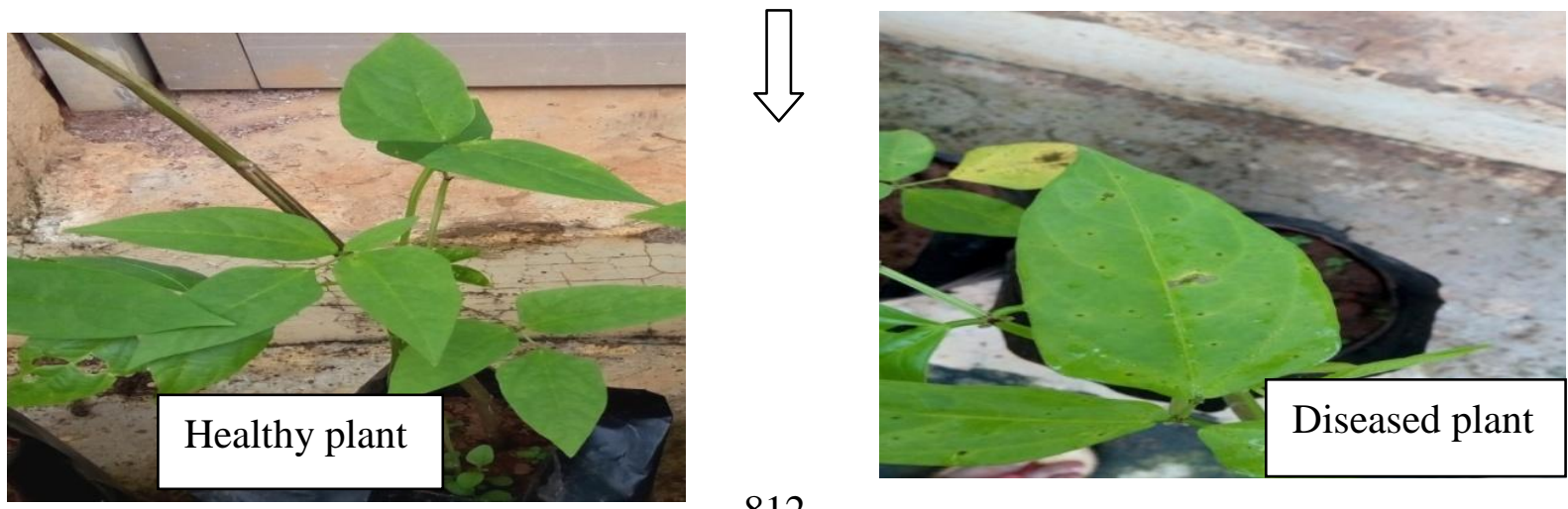
The first symptom in the field was characterized by presence of circular to irregular light brown or ashy coloured spots with dark brown margins. Later, the spots coalesced with each other to form a large patch in the leaves.

On pathogenicity, the causal fungus could induce the typical symptoms on the test plants at 4-5 days after artificial inoculation. However, the plants without inoculation did not exhibit any such symptoms. Thus, it proved Koch's postulate.

Morphological studies revealed that the conidia are fusiform, pale to mid dark brown, widened at the middle, gradually tapering to round ends possessing 2-3 pseudosepta.

The conidiophores are solitary or in groups, emerging from dark brown to black stromata, straight or flexous, sometimes geniulate, light to dark brown and pale near apex and smooth. The dimension of the conidia is in the range of 13.0-32.0 $\mu \mathrm{m} \times 5.1-11.0 \mu \mathrm{m}$ with an average range of $22.5 \mu \mathrm{m} \times 8.05 \mu \mathrm{m}$.

\section{References}

Barnett HL and Hunter BB. 1972. Illustrated Genera of Imperfect Fungi. 3rd Edition, Burgess Publishing Co., Minneapolis, $241 \mathrm{p}$.

Cobley LS and Steele WM. 1975. An Introduction to the Botany of Tropical Crops (London: Longman), 371 pgs.

Ellis MB. 1971. Dematiaceous Hyphomycetes. Kew, England: Comm. Mycol. Inst. Kew, Surrey, UK, pp. 932934.

\section{How to cite this article:}

Sahoo, S. and Beura, S.K. 2019. Helminthosporium vignicola- A New Report of Target Leaf Spot Disease of Cowpea Vigna unguiculata (L.) Walp. from Odisha, India. Int.J.Curr.Microbiol.App.Sci. 8(04): 809-813. doi: https://doi.org/10.20546/ijcmas.2019.804.090 